\title{
Anabases
}

ANABASES Traditions et réceptions de l'Antiquité

$17 \mid 2013$

Varia

\section{Laurent OLIVIER, Nos ancêtres les Germains. Les archéologues au service du nazisme}

\section{Catherine Valenti}

\section{OpenEdition}

Journals

Édition électronique

URL : http://journals.openedition.org/anabases/4291

DOI : 10.4000/anabases.4291

ISSN : 2256-9421

\section{Éditeur}

E.R.A.S.M.E.

\section{Édition imprimée}

Date de publication : 1 mars 2013

Pagination : 300-302

ISSN : 1774-4296

\section{Référence électronique}

Catherine Valenti, «Laurent oLIVIER, Nos ancêtres les Germains. Les archéologues au service du nazisme », Anabases [En ligne], 17 | 2013, mis en ligne le 01 avril 2013, consulté le 22 septembre 2020. URL: http://journals.openedition.org/anabases/4291 ; DOI : https://doi.org/10.4000/anabases.4291

Ce document a été généré automatiquement le 22 septembre 2020.

(c) Anabases 


\title{
Laurent OLIVIER, Nos ancêtres les Germains. Les archéologues au service du nazisme
}

\author{
Catherine Valenti
}

\section{RÉFÉRENCE}

Laurent OLIVIER, Nos ancêtres les Germains. Les archéologues au service du nazisme, Paris, Tallandier, 2012, $314 \mathrm{p}$. 20,90 euros / ISBN 978-2-84734-960-3.

1 Science identitaire destinée à exclure l'« Autre », l'archéologie nazie a construit une vision du passé sous-tendue par un postulat idéologique : celui de la présence partout en Europe, dès l'époque préhistorique, de peuplements anciens de " race germanique ». Les archéologues allemands, dans les années 1930-1940, se sont ainsi efforcés de mettre au jour les vestiges de ces "Indo-Germains ", selon la terminologie apparue dès les années 1820 pour désigner les locuteurs d'une hypothétique langue fondatrice (Ursprache) diffusée par un peuple originel censément doté d'aptitudes supérieures.

2 Au fil d'une douzaine de chapitres marqués parfois par quelques répétitions - ainsi l'auteur revient-il à deux reprises, dans les chapitres 7 et 8 , sur la conception nazie, il est vrai surprenante, d'un mégalithisme breton d'origine germanique, héritier d'ancêtres «indo-germains » du II ${ }^{\mathrm{e}}$ millénaire av. J.-C. -, Laurent Olivier aborde successivement trois grands thèmes. Il s'intéresse d'abord aux pratiques d'une archéologie nazie directement inspirée, au-delà des thèses d'un Gobineau, par les travaux de Gustaf Kossinna (1858-1931), inventeur d'une " archéologie de peuplement » qui, le premier, donne des matériaux archéologiques une interprétation biologique : les vestiges matériels des civilisations passées sont ainsi pensés par les nazis en termes d'identité ethnique et raciale. L'auteur évoque ensuite l'attitude des archéologues allemands à l'égard des territoires soumis par l'Allemagne au cours du second conflit 
mondial, et notamment leurs efforts pour démontrer que la France est une terre ancestrale de colonisation germanique : la détermination de l'histoire du peuplement "germanique " des régions situées à l'Ouest de l'Allemagne, en particulier sur le territoire français, constitue en effet une question essentielle pour assurer la légitimation "scientifique " des politiques d'expansion territoriale menées par le III ${ }^{\mathrm{e}}$ Reich. Enfin dans une troisième partie, l'auteur envisage les rapports entre l'archéologie française et le nazisme, évoquant d'abord la fascination des mouvements indépendantistes français pour l'idéologie nazie : ainsi le chapitre 10 est-il consacré à Jean-Jacques Thomasset, «le prophète de la Bourgogne germanique "; Olivier montre aussi comment, sous le régime de Vichy, l'archéologie française a été réorganisée sur le modèle allemand, même si les finalités poursuivies étaient sensiblement différentes : contrairement au $\mathrm{III}^{\mathrm{e}}$ Reich, Vichy fait passer au second plan l'archéologie préhistorique au profit du passé gaulois, dont la glorification occupe une place prépondérante dans l'imagerie du pétainisme.

Ce n'est pas dans cette démonstration cependant que réside l'originalité de l'ouvrage de Laurent olivier: que l'archéologie, comme l'histoire en général, soit l'objet d'une instrumentalisation au service d'une idéologie quelle qu'elle soit, nul ne peut véritablement le contester aujourd'hui. Mais ce que révèle par ailleurs son essai, c'est d'abord l'adhésion massive et consciente des archéologues allemands au parti nazi : $86 \%$ d'entre eux ont été membres du NSDAP, ce qui en fait la profession la plus «nazifiée » de tous les milieux socio-professionnels de l'Allemagne des années 1930-1940. Surtout, l'ouvrage de Laurent Olivier s'attache à briser l'omerta qui pèse selon lui depuis 1945 sur l'archéologie allemande mais aussi française, voire, au-delà, européenne: à de rares exceptions près, il n'y a pas eu après la Seconde Guerre mondiale d'épuration du milieu des archéologues, ni en Allemagne ni en France, et ce sont les mêmes hommes qui ont continué paisiblement à dominer les chaires d'archéologie de part et d'autre du Rhin. Certes, il n'était plus question après 1945 de démontrer l'existence d'un peuplement germanique originel de l'Europe; mais l'influence de l'archéologie nazie n'en est pas moins restée prégnante, non plus dans les problématiques mais dans les méthodes d'analyse et de traitement des vestiges archéologiques : nombres de techniques couramment utilisées aujourd'hui - inventaire systématique d'un chantier, sites pris non plus isolément mais considérés dans leur organisation de réseaux... - renvoient en réalité à l'« archéologie de peuplement » jadis pratiquée par les nazis, même si la finalité raciale n'est évidemment plus de mise. Laurent Olivier met également en relief des continuités plus pernicieuses: c'est la notion même de fait scientifique, comme production d'une information tangible et irrécusable, qui a été le plus durablement affectée par «le désastre du nazisme ». Selon l'auteur, en nous refusant encore aujourd'hui à mettre en cause la notion de véracité constitutive des faits archéologiques, nous nous condamnons à justifier comme véridique l'entreprise de perversion du passé menée par le nazisme. 


\section{AUTEURS}

\section{CATHERINE VALENTI}

Université de Toulouse (UTM)

catherine.valenti@univ-tlse2.fr 